\title{
L2 Academic Voices in Computer-Mediated Discourse*
}

\author{
Myung-Jeong Ha \\ Sangmyung University, Cheonan, South Korea
}

\begin{abstract}
This paper presents a case study that uses ethnographic and discourse analytic methods to examine the online interactional processes surrounding L2 (second language) socialization. Data for this paper come from a larger study of an academic classroom community of graduate students and their instructor. By employing the theory of L2 socialization, the author's study demonstrates how CMC (computer-mediated communication) space mediates a L2 learner's academic discourse socialization and is closely related to issues of agency and difference. For the purposes of this study, an important upshot of L2 socialization is that language serves as a means of socializing novice learners into linguistic behaviors expected of them in their new classroom community. By participating in the classroom practices aimed at gaining content knowledge, novice learners develop an understanding of what constitutes adequate competency in order to satisfy class requirements. The results of a case study of a Taiwanese ESL (English as a Second Language) student's online interaction with a group of class peers then show how this interaction relates to her developing agency in the new classroom community.
\end{abstract}

Keywords: language socialization, CMC (computer-mediated communication), higher education

\section{Introduction}

Although much of the previous L2 (second language) literature in the area of academic discourse socialization has mainly turned to academic writing activities and oral presentations, this study makes contributions by investigating the nature of academic online discourses, with a focus on group discussions in a graduate content course. By doing so, the author's study attempts to make a significant bridge between CMC (computer-mediated communication) and academic discourse socialization. In classroom settings, many studies on CMC during the last decade have focused on the benefits of CMC regarding its function that can change traditional power structures in the classroom and provide learning opportunities for students. However, there has been little of research on CMC that attempted to explore L2 learners' academic discourse socialization through online writing activities. The author's study thus attempts to provide a better understanding of how the affordances of computer communication problematize some of the earlier notions of interaction, culture, identity, and literacy within an academic classroom community, inspired by the recent trends of literacy highlighting that "a focus on language and literacy development as situated social processes... involves understanding the acquisition of language and literacies as always occurring in and through interactions with others in specific contexts” (Hawkins, 2005, p. 60).

\footnotetext{
* This study was supported by a 2013 Research Grant from Sangmyung University. Myung-Jeong Ha, assistant professor, Department of English Language and Literature, Sangmyung University.
} 
Contributing to a progression of recent $\mathrm{L} 2$ scholarship that has examined the connections between linguistic development and sociocultural contexts and relationships (e.g., Casanave, 2002; Norton, 2000), the author's study concentrates on the ways ESL (English as a Second Language) graduate students' academic literacy competencies are thriving in the computer-mediated discourse that links with larger social, rhetorical, and cultural contexts and then shapes their academic participation.

The research questions that guided the author's inquiry were: (1) How does a first-year L2 student negotiate her agency as she participate in online discussions?; and (2) What is her perception about her positions in the networked computer media?.

\section{Theoretical Framework}

The analysis of this CMC data, as in the larger study from which it originates, is informed by social theories, that is, language socialization (Duff, 1995; Ochs \& Schieffelin, 1984) and community of practice (Lave \& Wenger, 1991; Wenger, 1998). Language socialization theory has cast doubts on the conception of knowledge as a mental representation inside the individual's mind. Rather, language socialization theory stresses the construction of knowledge in social action. In language socialization theory, the locus of learning is the individual learners who are embedded in and are interacting with their social context. Its central goal is to understand better how to "become competent members of social groups and the role of language in the process" (Schieffelin \& Ochs, 1986, p. 167). With regard to the impact of language on socialization, this theory stresses the importance of language particularly in socializing novices in a sociocultural group (Duff, 1995).

Ochs and Schieffelin (2001) posited that the process of language acquisition and the process of socialization are inseparable, based on the notion that language is the medium by which to induct the individual into the stock of knowledge and practices of a community, and the acquisition of appropriate uses of language is part of gaining social competence in that community. For the purposes of this study, an important upshot of this notion is that language serves as a means of socializing ESL graduate students into linguistic behaviors expected of them in their new classroom community. By participating in the classroom practices aimed at gaining content knowledge, novice students develop an understanding of what constitutes adequate competency in order to satisfy class requirements. In light of this theory, we can assume that novice graduate students go through a process of academic socialization through the use of domain specialized language as they participate in literacy events, particularly CMC writing activities in my study. The author's study thus builds on the relatively recent literature about L2 language socialization and is premised on the idea that language socialization is a complex and multifaceted process in which negotiation of different discourses might be involved.

\section{Context}

The case study reported here is part of a larger ethnographic research of an academic classroom community of graduate students and their instructor at a large research university in the southwest of the US. The course was chosen as an information-rich case for the author's study grounded in the logic and power of purposeful sampling (Patton, 1990). As part of class requirement, students were given weekly articles to read and prepare prior to coming to class. The study focused on synchronous chat discussions for the entire 15 weeks of the Fall 2009 semester. 
With a total of 31 students enrolled in the class, 10 were non-native students and 21 were native students. Although NNS (Nonnative-Speaking) students' oral and written skills varied considerably, their English proficiency was deemed sufficiently high for the mainstream class. The current study concerns a first-year ESL graduate students (pseudonym) acquiring a disciplinary discourse of educational psychology in a mainstream classroom community. Because she was a newly arrived ESL student whose voice in English has not been completely established, the author chose her as the author's primary case to better understand her experience and attitudes as she makes transitions to the domain of computer-mediated discourse.

\section{The Focal Student}

Lynn was in the first semester as a doctoral student in the Foreign Language Education Program. Lynn was a 30+-year old Taiwanese female student. She was born and raised in Taiwan and had moved to the United States with her parents when she was entering a graduate school in New York. She had majored in English Literature at a university in Taiwan and continued on with her master's work in TESOL (Teaching English to Speakers of Other Languages) at a university in New York. After obtaining her master's degree, she taught EFL students for a few years and also worked as an editor of children's English books.

\section{Data Sources and Procedures}

The larger study drew on classroom observations and field notes, audiotaped interviews with focal students and the course instructor, course documents, CMC transcripts, background questionnaires, and end-of-semester questionnaires. Background questionnaires included some questions about the students' age, educational and professional backgrounds, their program of study, and their previous experiences with any course having a CMC component. The author conducted semi-structured interviews with the focal student within a week of an online discussion. She was asked to reflect on her online discussions in general and to talk about her experience and feelings in each online discussion. Then the author asked her about specific turns that the author noted prior to the interview. The author gave attention to places in the text where contextual cues or different voices seemed apparent. She was asked to produce a self-reflective essay on the online discussions as part of the class assignments. She was expected to describe the learning she experienced, and any linguistic, cognitive, affective, social, and cultural reactions that she had during the online discussions.

\section{Data Analysis}

Although data were collected in the whole class activities from beginning to end, this study focused on describing and interpreting the focal students' academic discourse socialization mediated by online discussions. The author chose a specific online task, synchronous CMC discussion, as the primary focus of analysis in this study. For the CMC written texts, the author drew on interactional sociolinguistics to examine how academic discursive practice is interrelated to the construction of learner agency and social relationships in the electronic exchanges produced by the focal students and their interlocutors. As the goal of the author's inquiry lay in describing the focal students' evolving participant roles, the author's analysis was widely guided by Goffman (1981) and Larson (1995).

\section{Results}

Results from the current study offer a rich description for understanding: (1) the agency of the focal 
participant in terms of the role she played in the classroom discourse highlighting the dialectical and interactional perspective of academic discourse socialization; and (2) student reactions and responses to the construction of participant roles during synchronous CMC activity.

\section{Construction of Participant Roles}

Of Lynn's 24 postings excluding the initial salutations, 12 postings included agreement with the previous speaker (e.g., “I agree”, “I do, too,” "it’s true”, “that’s true-I agree”, “I do agree with you”, “I am surprised, too", and "I cannot agree with you anymore"). Superficially, she frequently performed the role of agreer possibly in order to be acknowledged by her fellow interactants. The following example taken from her first online chat demonstrates her role as agreer (see Example 1):

Example (1)

Sequence 1.1

\#14 04:07:43 PM

Lynn:

hello

\#41 04:11:18 PM

Dorothy:

I am so happy to see you all here. So yes, let's talk about Sidiridis. So what did you think of the EMOTIONS he saw as related to the different goal orientations? A little predictable but so nice that he thought of that, I thought.

\#48 04:12:19 PM

Nick:

it would be hard to talk about motivation without addressing emotion, I think.

\#51 04:13:03 PM

Lynn:

I agree with Nick.

\#74 04:18:02 PM

Nick:

In a foreign language, I might be high performance-approach for writing and high performance avoid for speaking \#78 04:19:08 PM

Lynn:

I agree, especially for adult learners, they are high performance-approach for writing and reading than speaking and listening. (personal communication, September 16, 2009)

In sequence 1.1, Lynn's role of agreer to the previous speaker, Nick, was manifested two times. In turn 51, she picked up Nick's response to Dorothy's topic initiation simply by saying, “I agree with Nick”. Once again, in turn 78, she took the role of agreer ("I agree") and then used the opportunity to draw an inference from Nick's posting about adult learners' tendency to adopt a performance-approach orientation in their learning. In so doing, Lynn's role was clearly that of agreer in the first online chat. In this role, she could be participated peripherally in the first session without affecting the main flow of topic distribution.

In the second online chat, however, she showed some variation in her role within the participation framework, suggesting that she was being enculturated into a new academic cultural production, that of online chat. Lynn not only performed the role of agreer but also played the role of questioner, informant, and challenger. It was found that she aligned with, questioned, expanded, and challenged the knowledge posted by others depending on the evolving participation structure. The following sequence taken from the second online chat demonstrates her changing roles (see Example 2). 
Example (2)

Sequence 1.2

10 04:12:12

Lynn:

Hello

24 04:14:55

Alicia:

Did anyone else have negative feelings regarding the handwriting article?

34 04:16:17

Dana:

I loved the handwriting article! It reminds me why people get so aggravated by websites that are non-intuitive. They don't have any bandwidth left to learn anything anymore.

36 04:16:39

Lynn:

I do, too. I like the handwriting article.

38 04:17:00

Dorothy:

Ah. I love this connection between the topic for today and what we're doing right now. SO SO much overload when we're in here. Hard to imagine that a person could fall asleep. But then, you can see how it would happen if you decided that you had to give up and not try to participate.

42 04:18:00

YANG:

Dorothy

I read Chinese too. During the activity, I found myself to read the Chinese character faster in mind than reading it out loud. It seemed less distraction. I think it's kind of interesting.

50 04:19:07

Lynn:

So, YANG. When you read the poster, did you find it hard to ignore the Chinese characters?

55 04:20:11

Lynn:

YANG—it was so hard for me not to pay attention to the meaning of the words. even though I kept telling myself to ONLY focus on the colors.

62 04:21:06

YANG:

Lynn,

I did, esp., the very first characters, but we get better very quickly, do you think so? It's like once you know the rule, you go with the flow.

72 04:22:50

Lynn:

YANG—probably you're right. But, I wonder the speed for me to either read English or Chinese words would be different? What do you think?

88 04:25:34

YANG:

Lynn,

I think it also depends on how long you have been exposing in English. I learned my ABC since 13. And you?

110 04:31:15

Lynn:

YANG, 13... so that is a junior high school level. But, many parents in Asia tend to send their young kids to an after-school program to learn English. I think it’s probably related to how often you use the language, right? So, how long have you been here?

118 04:33:11 
YANG:

Lynn,

I didn't have any those after-school English classes, because our teacher forced us to attend her Chinese after-school class. (personal communication, September 30, 2009)

In the above sequence, in turn 34, Dana developed a "primary dyad" (Larson, 1995) by responding to Alicia’s question. In turn 36, Lynn took the role of agreer to Dana’s comment by saying, "I do, too". She then shifted roles and moved to the role of questioner in a way to respond to YANG's posting about reading the color of Chinese characters, an activity that had been done in class immediately prior to the synchronous chat. In turn 72, displaying her agreement with YANG's comment (“you're right”), Lynn also played the role of questioner to seek YANG's response in comparing the speed of reading English and Chinese ("What do you think?”). In turn 110, as a way of responding to YANG's turn 88, Lynn posed another question to seek information ("So how long have you been here?"), which was then followed by YANG's response (turn 118).

Furthermore, Lynn moved to the role of challenger to show her disagreement with a peer's comment. The following sequence was taken from the same context as the above one in her second online chat (see Example 3).

Example (3)

Sequence 1.3

89 04:26:22

Dorothy:

YANG-That IS interesting about your experience of doing the Stroop task in your head. Of course, we don't know if you were accurate right? ;-) But it may be that producing the word DOES take time.

95 04:28:02

YANG:

Dorothy,

Yes, you are absolutely right. I just think that most of the time when we read, we don't read out loud. It eliminates distraction.

135 04:35:17

Lauren:

YANG, Reading out loud eliminates distraction?

144 04:37:43

Lynn:

I don't think reading out loud will eliminate distraction—on the other hand, it will probably increase distraction. I've read an article about how fast you speak, how fast you read—I somehow doubt it. (personal communication, September 30, 2009)

Instead of overtly negating YANG's view, Lauren challenged YANG by posing a question ("Reading out loud eliminates distraction?”, turn 135), suggesting that she saw things differently. In turn 144, Lynn played the role of challenger by overtly disagreeing with YANG's perspective that reading out loud eliminates distraction (turn 95). In addition, Lynn presented counter evidence to support her disagreement ("I've read an article about how fast you speak, how fast you read”).

\section{Lynn's Perspectives to Her Positions in CMC}

Lynn displayed her sense of discomfort in engaging in online discussions as she transitioned into the experience, and particularly described the first online chat as an "obligation”. Lynn reported that she experienced feelings of "loss and helplessness" during the first synchronous session because she felt she had totally failed to do what she needed to get started, overwhelmed with the great number of statements appearing on the screen in a very short time. 
Synchronicity and simultaneity of online chat mode generally caused her a "sense of anxiety" and that, as a result, she was "completely lost and had no idea" of what she needed to do in engaging in the online chat. When she was asked about any perceived difficulties in participating in the online discussions as a non-native speaker, she said:

I've never thought about that kind of question before, but I would consider myself as kind of like a slow person, because every time when I have to respond a question or whatever, it takes me time to think about that. So, I really have no idea if it's because of the language because I'm not a native speaker, or it's just because of my personality. (interview, September 25, 2009)

As Lynn regarded herself as "a slow person", her individual orientation to a relatively slow rate of processing may not have been a good fit for synchronous chatting. Although she felt that she needed to adjust to the fast onslaught of topics in the synchronous discussion to survive in the course, Lynn could not figure out in the first chat any coping strategy to be included or manage the online chat. The teacher's feedback after the first synchronous discussion became an important turning point for her personal transformation in online chat participation. Her change was manifested in her self-reflective essay as follows:

Even though I tried to respond to the statement that draw my attention or I had a strong reaction to it, I erased it right away because once I finished typing my statement, there were many new statements posted within seconds—so at that time, I thought it was not a good idea responding to a question or statement that was already found somewhere on the screen. However, after our first session, the professor encouraged us not being afraid of posting any statement even if it was late (I found her comment useful). So I was able to get involved more in other synchronous discussions afterwards. (Self-reflective Essay, December 12, 2009)

As she mentioned, there was a large difference in the variety of roles she took on in participating between her first online chat and the other online chat sessions in which she was involved.

\section{Conclusions and Implications}

In classrooms characterized by a variety of student populations, role negotiation can often create tensions and uncertainties (Morita, 2004). The author described how Lynn, the first year graduate student, interacted with her new academic context, more specifically, online chat, as active human agent with her unique personal history, values, and expectations. The focal student' agency was enacted in various ways as a result of interacting with the sociocultural, temporal, and institutional world surrounding them, in this case, other online chat participants.

The process of socialization has often been described as ideal and seamless, and novice learners were often characterized as inactive, ready, and uniform receivers of socialization. For example, in light of language socialization theory (Ochs \& Schieffelin, 1984), traditional models of expert-novice relationships have maintained the assumption that Oldtimers are always willing to share their expertise with newcomers and that newcomers learn by more competent members' assistance and guidance. Given these assumptions, much past research has tended to focus on the experts' role in socializing the novice learners. It is not uncommon that much less visible are the reactions and responses on the side of the novice learners themselves. As Lynn continued to be proactive in dealing with the challenges of adjusting to the new classroom culture of online chat, she experienced some personal transformation in the roles she took on in the participation structure of the online discussion as the semester was on. The notion of gaining access to fuller participation in the online chat 
is connected to as "legitimate peripheral participation" what Lave and Wenger (1991) referred to. Changes in her role toward more intensive participation constituted learning trajectories and forms of membership (Lave \& Wenger, 1991). Grounded in Lave and Wenger’s perspective, Lynn gained access to in-group interaction and moved toward fuller participation through her personal transformation as she joined the in-group.

An important theoretical implication can be drawn as a result of this study. The primary issue relates to the application of the language socialization framework to non-native graduate students' academic literacy trajectories. Although other L2 researchers (e.g., Duff, 2003; Morita, 2000, 2004; Spack, 1997) have illustrated the usefulness of this theory to examine mainly traditional literacy practices such as academic writing or oral presentations, the author's data suggested that socialization through online academic practices can be an important arena of research.

This study thus constituted a new attempt to extend the language socialization framework to the domain of online academic literacy. To that end, the goal was to provide a rich description of the locally situated nature of intellectual activities, thereby suggesting an alternative approach to the notion of academic discourse socialization, which is different from the traditional researchers' product-oriented, context-reduced, and value-free stance.

\section{References}

Casanave, C. P. (2002). Writing games: Multicultural case studies of academic literacy practices in higher education. Mahwah, N.J.: Erlbaum.

Duff, P. A. (1995). An ethnography of communication in immersion classrooms in Hungary. TESOL Quarterly, $29,505-537$.

Duff, P. A. (2003). New directions in second language socialization research. Korean Journal of English Language and Linguistics, 3, 309-339.

Goffman, E. (1981). Forms of talk. Philadelphia: University of Pennsylvania Press.

Hawkins, M. R. (2005). Becoming a student: Identity work and academic literacies in early schooling. TESOL Quarterly, 39(1), 59-80.

Larson, J. (1995). Talk matters: The role of pivot in the distribution of literacy knowledge among novice writers. Linguistics and Education, 7(4), 277-302.

Lave, J., \& Wenger, E. (1991). Situated learning: Legitimate peripheral participation. Cambridge, M.A.: Cambridge University Press.

Morita, N. (2000). Discourse socialization through oral classroom activities in a TESL graduate program. TESOL Quarterly, 34, 279-310.

Morita, N. (2004). Negotiating participation and identity in second language academic communities. TESOL Quarterly, 38, 573-603.

Norton, B. (2000). Identity and language learning: Gender, ethnicity and educational change. London: Longman/Pearson.

Ochs, E., \& Schieffelin, B. B. (1984). Language acquisition and socialization: Three developmental stories and their implications. In R. A. Schweder \& R. A. LeVine (Eds.), Culture theory: Essays on mind, self, and emotion (pp. 276-322). New York: Cambridge University Press.

Ochs, E., \& Schieffelin, B. B. (2001). Language acquisition and socialization: Three developmental stories and their implications. In A. Duranti (Ed.), Linguistic anthropology: A reader (pp. 263-301). Oxford, UK: Blackwell.

Patton, M. Q. (1990). Qualitative evaluation methods. Thousand Oaks, C.A.: Sage.

Schieffelin, B., \& Ochs, E. (1986). Language socialization. Annual Review of Anthropology, 15, 163-191.

Spack, R. (1997). The rhetorical construction of multilingual students. TESOL Quarterly, 31, 765-774.

Wenger, E. (1998). Communities of practice: Learning, meaning, and identify. Cambridge: Cambridge University Press. 